Research Article

\title{
Nickel-phenanthroline Complex Supported on Mesoporous Carbon as a Catalyst for Carboxylation under $\mathrm{CO}_{2}$ Atmosphere
}

\author{
Iman Abdullah ${ }^{1, *}$, Riri Andriyanti ${ }^{1}$, Dita Arifa Nurani ${ }^{1}$, Yuni Krisyuningsih Krisnandi ${ }^{1,2}$ \\ ${ }^{1}$ Department of Chemistry, Faculty of Mathematics and Natural Sciences, Universitas Indonesia, \\ Depok 16424, Indonesia. \\ ${ }^{2}$ Solid Inorganic Framework Laboratory, Department of Chemistry, Faculty of Mathematics and \\ Natural Sciences, Universitas Indonesia, Depok 16424, Indonesia.
}

Received: $10^{\text {th }}$ December 2020; Revised: 28 ${ }^{\text {th }}$ February 2021; Accepted: $1^{\text {st }}$ March 2021 Available online: 3rd March 2021; Published regularly: March 2021

\section{Abstract}

Carbon dioxide is a highly potential renewable $\mathrm{C}_{1}$ source for synthesis of fine chemicals. Utilization of $\mathrm{CO}_{2}$ in carboxylation reactions requires catalysts, such as: nickel complex for $\mathrm{CO}_{2}$ activation. However, the use of homogeneous catalysts in the reaction is still less efficient due to the difficulty of separating the product and catalyst from reaction mixture. Therefore, it is necessary to heterogenize the nickel complex in a solid support such as mesoporous carbon. In this report, mesoporous carbon (MC) prepared from phloroglucinol and formaldehyde through soft template method was used as a solid support for Ni-phenanthroline complex (Ni-phen). The catalyst was characterized by Fourier Transform Infra Red (FT-IR), X-Ray Diffraction (XRD), Scanning Electron Microscope - Energy Dispersive X-Ray (SEM-EDX), and Surface Area Analyzer (SAA). The result of SAA characterization showed that the pore diameter of MC was $6.7 \mathrm{~nm}$ and Ni-phen/MC was $5.1 \mathrm{~nm}$ which indicates that the materials have mesosize pores. Ni-phen/MC material was then used as a heterogeneous catalyst in the carboxylation reaction of phenylacetylene under an ambient $\mathrm{CO}_{2}$ pressure. The reactions were carried out in several variations of conditions such as temperature, time and catalyst types. Based on the results of the reaction, the best conditions were obtained at $25^{\circ} \mathrm{C}$ for $8 \mathrm{~h}$ of reaction time using $\mathrm{Ni}$-phen/MC catalyst.

Copyright (C 2021 by Authors, Published by BCREC Group. This is an open access article under the CC BY-SA License (https://creativecommons.org/licenses/by-sa/4.0).

Keywords: carboxylation; $\mathrm{CO}_{2}$; mesoporous carbon; nickel complex; phenanthroline

How to Cite: I. Abdullah, R. Andriyanti, D.A. Nurani, Y.K. Krisnandi (2021). Nickel-phenanthroline Complex Supported on Mesoporous Carbon as a Catalyst for Carboxylation under $\mathrm{CO}_{2}$ Atmosphere. Bulletin of Chemical Reaction Engineering \& Catalysis, 16(1), 111-119 (doi:10.9767/bcrec.16.1.9733.111-119)

Permalink/DOI: https://doi.org/10.9767/bcrec.16.1.9733.111-119

\section{Introduction}

Carbon dioxide $\left(\mathrm{CO}_{2}\right)$ is a greenhouse gas which is quite abundant in nature and belongs to a non-flammable gas. $\mathrm{CO}_{2}$ has the potential to become a renewable $\mathrm{C}_{1}$ source for the synthe-

* Corresponding Author.

E-mail: iman.abdullah@sci.ui.ac.id (I. Abdullah); Telp: +62-21-7270027 sis of useful chemicals given its high abundance as well as its low price [1]. To date, the most widely used carbon resources in the production of fine chemicals are obtained from conventional sources such as crude oil, natural gas, and coal [2]. Thus, utilization of $\mathrm{CO}_{2}$ in this field is a promising and attractive method to continue to be developed. However, the use of $\mathrm{CO}_{2}$ as a carbon resource has several obstacles due to its in- 
ert nature and low reactivity. In fact, most reactions involving $\mathrm{CO}_{2}$ requires stoichiometric amounts of catalysts or harsh reaction conditions. Therefore, the development of a new and efficient catalytic system for the chemical transformation of $\mathrm{CO}_{2}$ is one of the interesting topics in modern organic synthesis [3].

Nickel is a transition metal that has been widely used as catalyst for various transformations both in organic and inorganic reactions. In addition, nickel complexes have been widely employed as homogeneous catalyst in carboxylation reaction of various substrates with $\mathrm{CO}_{2}$ [4]. The reaction occurs through formation of a $\mathrm{C}-\mathrm{C}$ bond to produce a carboxylic acid or its derivatives. For example, carboxylation reaction of aryl and vinyl chloride with $\mathrm{CO}_{2}$ using $\mathrm{Ni}$ complex catalysts was reported by Fujihara et al. [5]. The reactions were conducted with an atmospheric $\mathrm{CO}_{2}$ at room temperature in the presence of $\mathrm{Mn}$ powder as a reducing agent. The reaction system gave good yield of product and is suitable for various types of aryl chloride. A double carboxylation reaction of alkynes with $\mathrm{CO}_{2}$ using $\mathrm{Ni}$ complex catalyst was also reported by the same research group [6]. The reaction was conducted also in an athmospheric $\mathrm{CO}_{2}$ gas in the presence of $\mathrm{Zn}$ powder as a reducing agent and $\mathrm{MgBr}_{2}$ as an additive to facilitate the second insertion of $\mathrm{CO}_{2}$. Various aliphatic alkynes were suitable as the substrate for the double carboxylation giving a substituted maleic anhydride as the product. Similar system was also reported to be suitable for hydrocarboxylation of ynamides as substrate in the present of small amount of water as proton source to give an $\alpha$-carboxylation product as a major product [7]. Whereas the presence of organozinc as reducing agent in the $\mathrm{Ni}$-catalytic system gave $\beta$-carboxylation compound as the product for the same type of substrate [8].

It is known that a homogenous catalyst has the advantage in the reaction process since the reactants and the catalyst being in the same phase and the reaction occurs in all phases. Thus, in most cases, homogeneous catalyst shows higher activity than the heterogeneous for the same reaction. However, homogeneous catalysis system has several drawbacks such as the need for additional costs for separation of product from the catalyst and reaction mixture, the short lifetime of the catalyst (difficult to recover) and the relatively expensive price of the catalyst itself. Therefore, the use of heterogeneous catalysts is becoming more desirable especially for applications on an industrial scale.
Mesoporous carbon is a class of porous nanomaterials having large pore size, which are around 2-50 nm [9]. The research of mesoporous carbon has long been carried out with various precursors such as sucrose [10], furfuryl alcohol [11], phenolic resin [9,12], glycerol [13], and gelatin [14]. It is known that mesoporous carbon shows some unique properties such as a controllable structure and pore size, high surface area, and high thermal and chemical stability. Thus, mesoporous carbon promises to be used as a supporting solid for heterogenization of nickel complex. The forming heterogeneous nickel complex could then be explored its activity in carboxylation reaction employing $\mathrm{CO}_{2}$ as a $\mathrm{C}_{1}$ carbon source. On our previous report, we succeeded the synthesis of $\mathrm{Ni}$ metal supported on mesoporous carbon [15]. However, the Ni/MC catalyst was not effective for carboxylation reaction under an atmospheric $\mathrm{CO}_{2}$ pressure. We speculated that the limited exposure to the $\mathrm{Ni}$ metal as the active site causes the low catalytic activity of the catalyst system. Therefore, the use of complex nickel species supported on MC is expected to provide better catalytic activity since it has more exposed sides, thus it can interact with the reactants better.

In this research, we prepared the mesoporous carbon by soft template method, and then used as solid support for heterogenization of nickel-phenanthroline complex. We then explored the catalytic activity of the Ni-phen/MC for carboxylation reaction of phenylacetylene in an athmospheric $\mathrm{CO}_{2}$. Prior to catalytic activity, we also investigated the adsorption ability of the material towards $\mathrm{CO}_{2}$.

\section{Materials and Methods}

\subsection{Materials}

All materials were used in the experiments without additional purification. Phloroglucinol $99 \%$, ethanol $99.8 \%$, hydrochloric acid $(\mathrm{HCl})$ $37 \%$, and formaldehyde $37 \%$ were provided by Merck, while Pluronic F-127, 1,10phenanthroline $98 \%, \mathrm{Ni}\left(\mathrm{NO}_{3}\right)_{2} .6 \mathrm{H}_{2} \mathrm{O}$, magnesium bromide $98 \%$, Zn powder, DMF $99.8 \%$, and phenylacetylene $98 \%$ were obtained from Sigma Aldrich. Ultrahigh pure $\mathrm{N}_{2}$ and $\mathrm{CO}_{2}$ gases were used for carbonization and carboxylation, respectively, and were purchased from $\mathrm{CV}$ Retno Gas.

\subsection{Synthesis of Mesoporous Carbon (MC)}

Mesoporous carbon was synthesized using a previously reported procedure [9]. Briefly, 
$6.2595 \mathrm{~g}$ phloroglucinol precursor and $6.286 \mathrm{~g}$ Pluronic F-127 were dissolved in ethanol:water $(25.6: 22.6 \mathrm{~mL})(\mathrm{w} / \mathrm{w})$ solution and stirred vigorously at room temperature. After a complete copolymer dissolution, $0.4 \mathrm{~mL} \mathrm{HCl} \mathrm{37 \%} \mathrm{(w/w)}$ was added, and the solution was vigorously stirred for $30 \mathrm{~min}$. Under continuous stirring, $6.25 \mathrm{~mL}$ formaldehyde $37 \%$ was added to the mixture. Then, the mixture was stirred for another 2 hours until being separated into two layers followed with decantation process to separate residue and filtrate. Then monolith (the bottom layer) was transferred to an autoclave for hydrothermal process in an oven at $100{ }^{\circ} \mathrm{C}$ for 24 hours. The resulting material was carbonized with a tubular furnace under the stream of $\mathrm{N}_{2}$ gas with a heating rate of 1 ${ }^{\circ} \mathrm{C} / \mathrm{min}$ from 100 to $400{ }^{\circ} \mathrm{C}$ and $5{ }^{\circ} \mathrm{C} / \mathrm{min}$ from $400-850^{\circ} \mathrm{C}$ before kept at $850{ }^{\circ} \mathrm{C}$ for 2 hours. The synthesized mesoporous carbon was characterized with FTIR (Shimadzu IR Prestige 21), XRD (PANalytical X'Pert PRO), SEM-EDX (JEOL JED-2300 Analysis Station), and SAA (Quantachrome Quadrasorb-Evo Surface Area and Pore Size Analyzer).

\subsection{Immobilization of Ni-phenanthroline Com-} plex to MC (Ni-phen/MC)

First, 0.3064 g 1,10-phenanthroline and $0.4954 \mathrm{~g} \mathrm{Ni}\left(\mathrm{NO}_{3}\right)_{2} .6 \mathrm{H}_{2} \mathrm{O}$ were dissolved in $4 \mathrm{~mL}$ deionized water $(\mathrm{w} / \mathrm{w})$ at room temperature. Under continuous stirring, 2 g mesoporous carbon was slowly added to the solution. The mixture was stirred for 6 hours followed with ultrasonication for $10 \mathrm{~min}$. The mixture was further stirred at room temperature for 24 hours and then dried in an oven at $60^{\circ} \mathrm{C}$ for 12 hours.

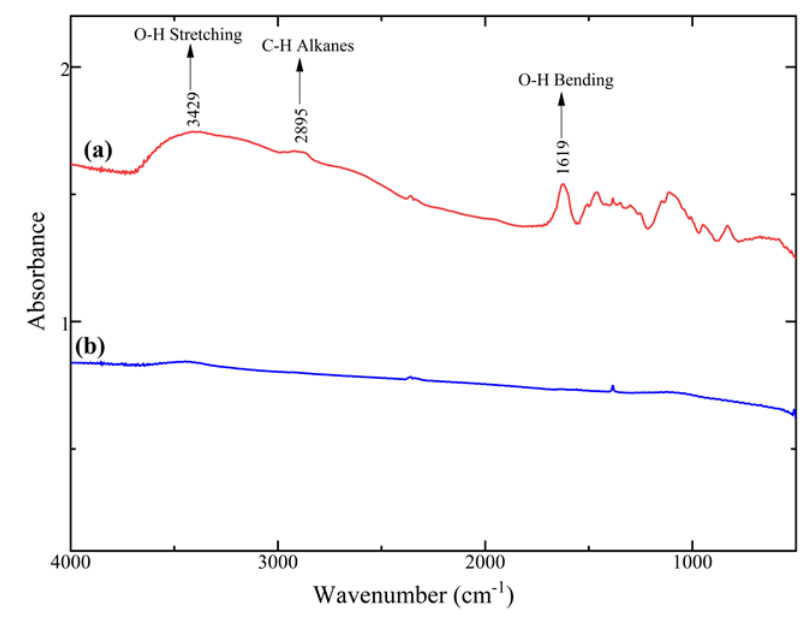

Figure 1. The spectrum of (a) monolith before carbonization, and (b) MC after carbonization.

\subsection{Adsorption of Carbon Dioxide $\left(\mathrm{CO}_{2}\right)$}

Carbon dioxide adsorption test was done following previously reported procedure [16]. $\mathrm{CO}_{2}$ gas was flown into the chamber containing a $0.1 \mathrm{~g}$ sample (MC or Ni-phen/MC) with a flow rate of $50 \mathrm{~cm} 3 / \mathrm{min}$, at a pressure of 1 bar with various time $(5,10$, and $15 \mathrm{~min})$. The unadsorbed $\mathrm{CO}_{2}$ gas was collected in $100 \mathrm{~mL} 0.1 \mathrm{M}$ $\mathrm{NaOH}$ solution at the temperature of $\pm 2{ }^{\circ} \mathrm{C}$. Quantitative analysis of the amount of $\mathrm{CO}_{2}$ in the solution was done using a titration method. $10 \mathrm{~mL} 0.1 \mathrm{M} \mathrm{NaOH}$ solution was titrated with $0.1 \mathrm{M} \mathrm{HCl}$. The titration was conducted using phenolphthalein and methyl orange indicator to detect the first and second equivalent points.

\subsection{Carboxylation Reaction of Phenylacetylene} with $\mathrm{CO}_{2}$

The carboxylation reaction was conducted in a glass reactor connected to a $\mathrm{CO}_{2}$ gas balloon. The procedure adopted previously reported method [15,17]. To the reactor was added $0.0654 \mathrm{~g} \mathrm{Zn}$ powder, $0.1841 \mathrm{MgBr}_{2}, 0.011 \mathrm{~g} \mathrm{Ni}$ phen/MC as a catalyst, $4 \mathrm{~mL} \mathrm{DMF}$ as a solvent and $0.112 \mathrm{~mL}$ phenylacetylene as the substrate. Then the reactor was connected to a $\mathrm{CO}_{2}$ balloon, and the mixture was stirred at a certain temperature $\left(25,50\right.$, and $\left.75^{\circ} \mathrm{C}\right)$ for a specified time $(4,8$, and 16 hours). The carboxylation reaction was also conducted using MC (or Ni-phen complex) in place of Ni-phen/MC as comparison. After the reaction, $1 \mathrm{~mL} \mathrm{HCl} \mathrm{10 \%}$ was added to the mixture and was stirred for 10 min followed with filtration to separate residue and filtrate. The carboxylation product as well as the unreacted phenylacetylene were analyzed by HPLC with Diamonsil C18 column.

\section{Results and Discussion}

\subsection{Synthesis and Characterization of Catalyst}

The synthesis of MC was performed using a soft template method with phloroglucinol and formaldehyde precursor as a carbon source, Pluronic F-127 as a template or surfactant, ethanol-water solution as medium for pluronic F-127 self-assembly and $\mathrm{HCl} 37 \%$ as catalyst for the polymerization reaction of phloroglucinol and formaldehyde. The hydrothermal treatment of the resulting monolith (polymerized form of carbon precursor) aims to the formation of meso-size pore and structure of mesoporous carbon. Whereas carbonization aims to polymer decomposition and to increase the surface area of mesoporous carbon [18]. The as-synthesized MC was then utilized as a solid support for Ni-phenanthroline complex. 


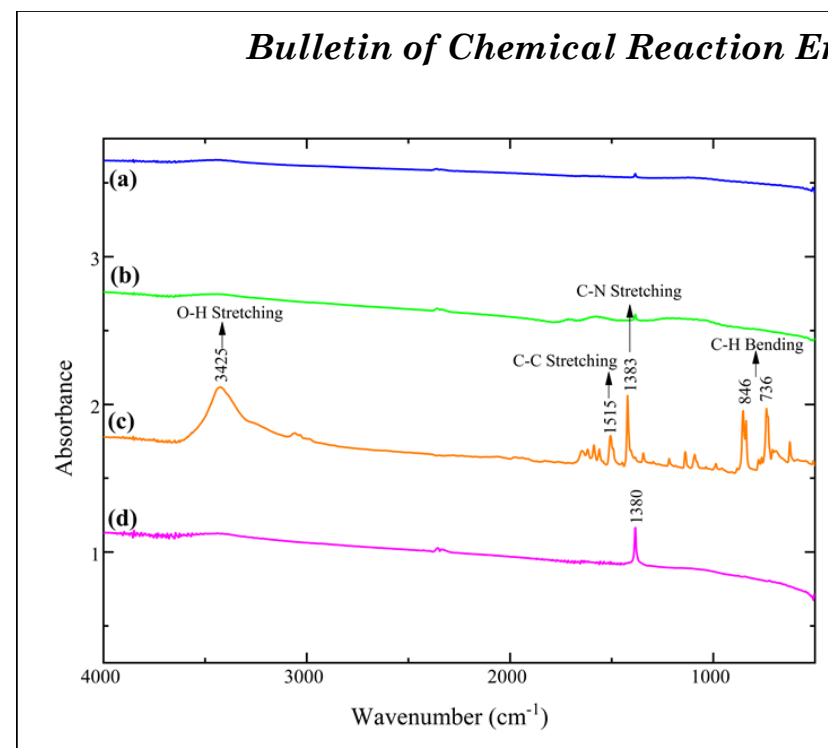

Figure 2. The spectrum of (a) mesoporous carbon (MC), (b) activated carbon (AC), (c) 1,10phenanthroline, and (d) Ni-phen/MC.
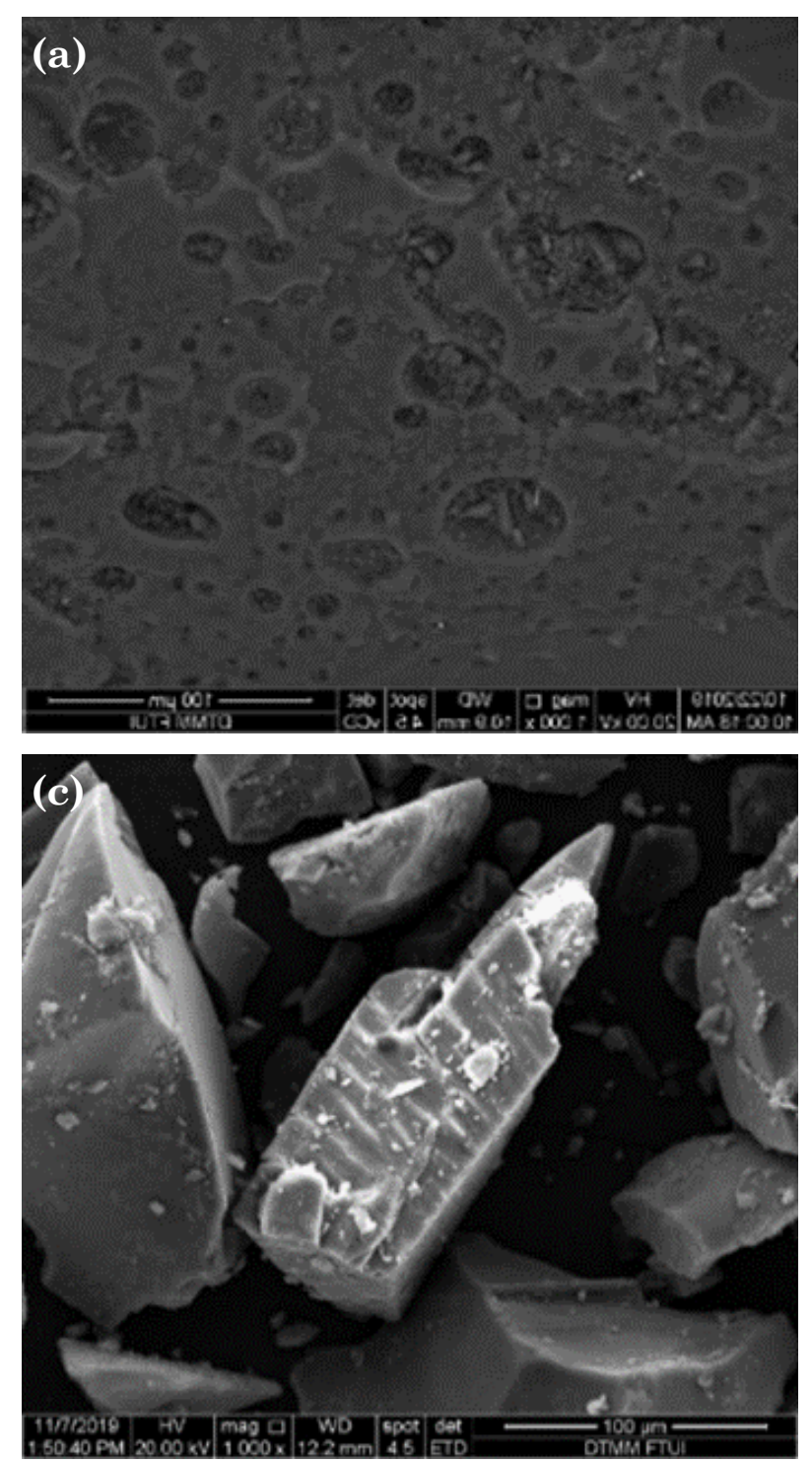

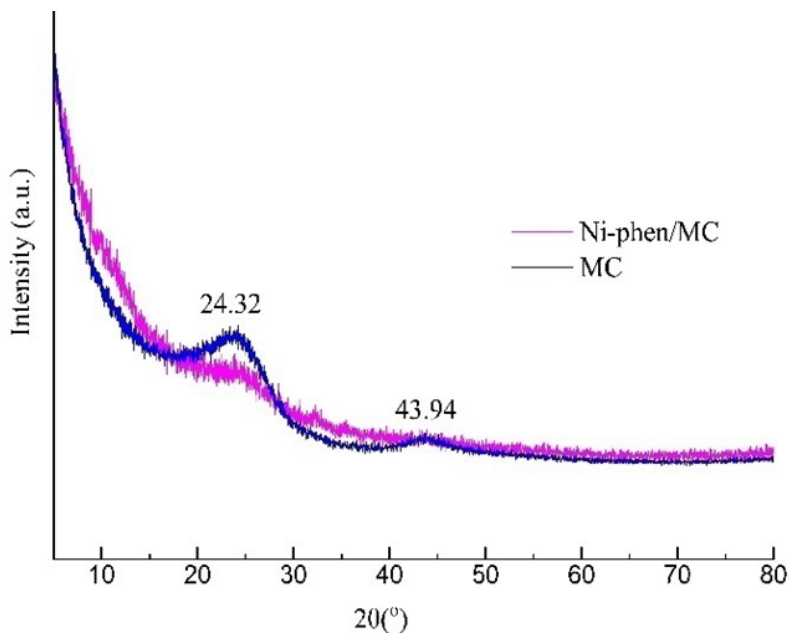

Figure 3. The XRD pattern of $\mathrm{MC}$ and $\mathrm{Ni}$ phen/MC materials.
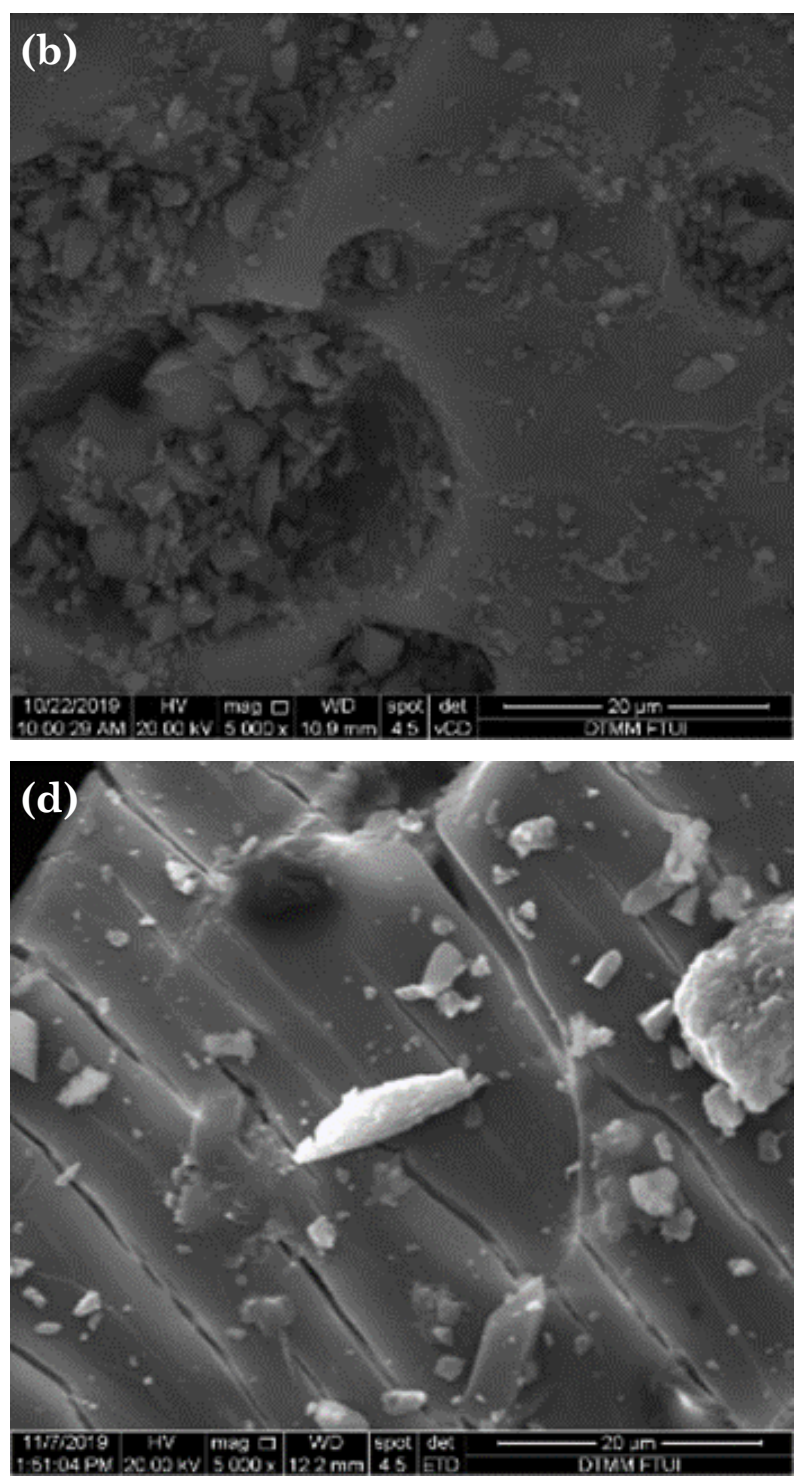

Figure 4. SEM image of (a) MC 1000X, (b) MC 5000X, (c) Ni-phen/MC 1000X, and (d) Ni-phen/MC 5000X magnification. 
The 1,10-phenanthroline bidentate ligan forms a chelating effect by formation of coordination bonding to nickel ion [19]. Physical interaction could occur between mesoporous carbon with aromatic ring of phenanthroline ligands to give a heterogenized Ni-phen/MC catalyst.

IR spectra in Figure 1 show that the carbonization process proceeded well. This can be observed from removal of some functional groups such as $\mathrm{O}-\mathrm{H}$ (stretching at $3429 \mathrm{~cm}^{-1}$; bending at $\left.1619 \mathrm{~cm}^{-1}\right)$ and $\mathrm{C}-\mathrm{H}$ alkanes $\left(2895 \mathrm{~cm}^{-1}\right)$ which come from the phloroglucinol and formaldehyde precursors. We also compare the FTIR spectrum of MC with activated carbon (AC), phenanthroline ligand, and Ni-phen/MC (Figure 2). The spectrum of MC and AC showed similar pattern which indicate that both materials have almost no functional groups on their surface. In contrast to MC, the IR spectrum of phenanthroline consist of some peaks related to $\mathrm{O}-\mathrm{H}$ stretching $\left(3425 \mathrm{~cm}^{-1}\right), \mathrm{C}-\mathrm{H}$ stretching $\left(3050 \mathrm{~cm}^{-1}\right), \mathrm{C}-\mathrm{C}$ stretching $\left(1515 \mathrm{~cm}^{-1}\right), \mathrm{C}-\mathrm{N}$ stretching $\left(1383 \mathrm{~cm}^{-1}\right)$, and $\mathrm{C}-\mathrm{H}$ bending $(846$ $\mathrm{cm}^{-1}$ ) as shown in Figure 2c. Interestingly, Niphen/MC shows only one sharp peak at 1383 $\mathrm{cm}^{-1}$ indicating the presence of $\mathrm{C}-\mathrm{N}$ group [20]. These results suggest that the Ni-phen complex has been incorporated into the MC structure. The absence of the absorption peak of $\mathrm{C}-\mathrm{H}$

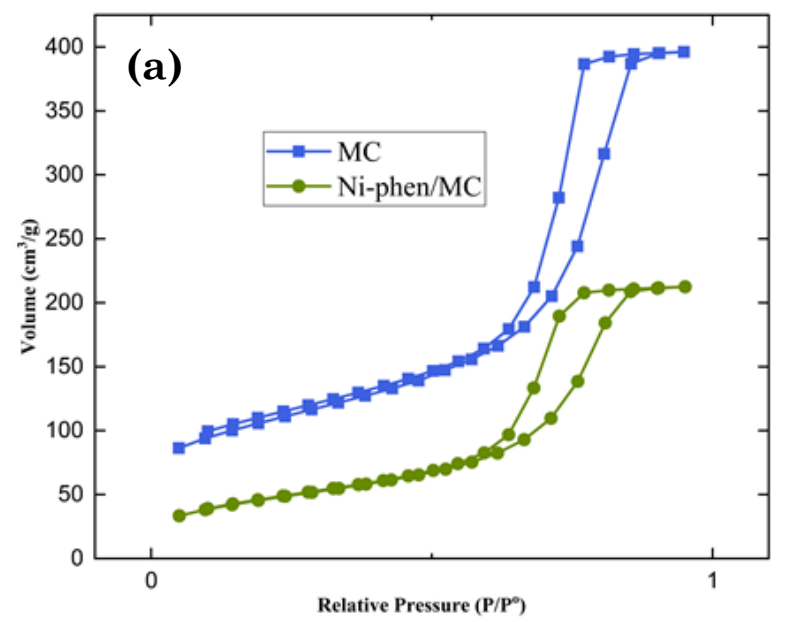

groups of phenanthroline indicates a strong interaction between aromatic ring of phenanthroline and mesoporous carbon.

The diffraction pattern of $\mathrm{MC}$ and $\mathrm{Ni}$ phen/MC material are shown in Figure 3. Two peaks appear at $2 \theta$ of $24.32^{\circ}$ and $43.94^{\circ}$ which are the typical peaks of mesoporous carbon. These peaks have indices of 002 and 100 [21]. The diffractogram shows that the materials have an amorphous structure, and there was no significant structure difference between MC and $\mathrm{Ni}$-phen/MC materials. Thus, the immobilization of Ni-phen complex does not alter the original structure of the mesoporous carbon.

The morphological and elemental analysis of $\mathrm{MC}$ and $\mathrm{Ni}$-phen/MC were conducted using SEM-EDX characterization. Figure 4 shows surface morphology of $\mathrm{MC}$ and Ni-phen/MC with 1000 and 5000 magnification. The Niphen/MC has a smooth morphology compared with MC. In addition, there are some white particles of various sizes on the surface of the $\mathrm{Ni}$-phen/MC indicating the presence of Ni-phen complex that has been attached to the surface of mesoporous carbon. Whereas Table 1 show the elemental composition on the surface of MC and Ni-phen/MC. According to the table, MC consist of $88.86 \% \mathrm{C}$ and $11.14 \% \mathrm{O}$ by weight. After the immobilization of Ni-phen complex,

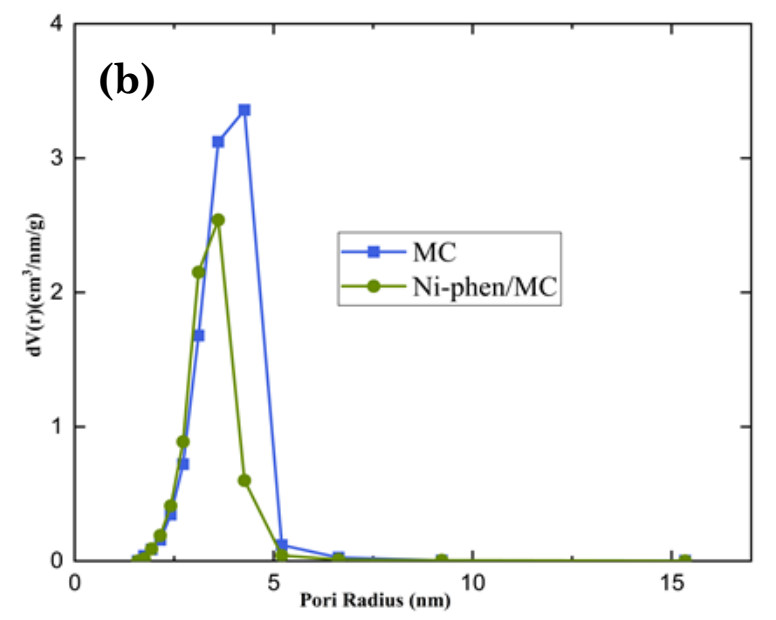

Figure 5. (a) adsorption-desorption isotherms curve of MC and Ni-phen/MC materials, (b) pore size distribution curve of MC and Ni-phen/MC.

Table 1. Elemental composition of MC and Ni-phen/MC by EDX.

\begin{tabular}{cccccc}
\hline \multirow{2}{*}{ Element } & \multicolumn{3}{c}{ MC } & & \multicolumn{2}{c}{ Ni-phen/MC } \\
\cline { 2 - 3 } \cline { 5 - 6 } & Mass (\%) & Atom (\%) & & Mass (\%) & Atom (\%) \\
\hline $\mathrm{C}$ & 88.86 & 91.4 & & 88.06 & 92.14 \\
$\mathrm{O}$ & 11.14 & 8.6 & & 8.67 & 6.79 \\
$\mathrm{Ni}$ & - & - & & 3.27 & 1.06 \\
\hline
\end{tabular}


$\mathrm{Ni}$ element was detected with a content of $3.27 \%$ which proves the immobilization of the complex on the surface of MC.

Nitrogen adsorption-desorption isotherm curve of $\mathrm{MC}$ and $\mathrm{Ni}$-phen/MC are shown in Figure 5(a). The curves show that the two materials have similar type IV of hysteresis loops which is a typical curve for mesoporous material. However, as shown in Figure 5(b) there is a decrease in pore radius of the material after immobilization of the $\mathrm{Ni}$ complex, from 3.36 to $2.54 \mathrm{~nm}$. This result indicates that some $\mathrm{Ni}$ complex enter the pores, thereby reducing the average pore diameter. In addition, there is also a decrease in the surface area of Ni-phen/MC which was most likely due to the partial filling of the carbon pores by the Ni complex. The surface properties of $\mathrm{MC}$ and $\mathrm{Ni}$-phen/MC are summarized in Table 2.

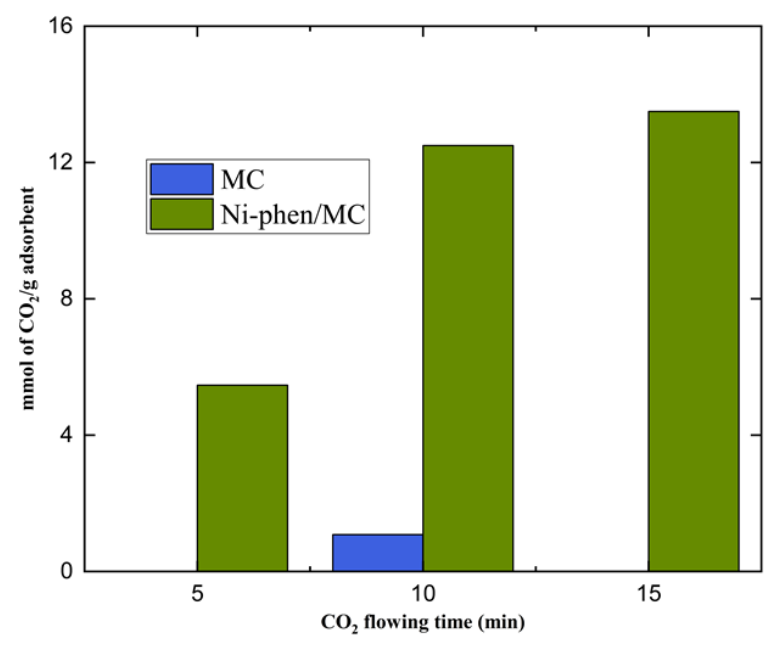

Figure 6. The result of adsorption of $\mathrm{CO}_{2}$.

\subsection{Adsorption of Carbon Dioxide $\left(\mathrm{CO}_{2}\right)$}

The adsorption performance of Ni-phen/MC towards $\mathrm{CO}_{2}$ is presented in Figure 6. Based on the figure, the longer the flow of $\mathrm{CO}_{2}$ to the sample, the greater the amount of $\mathrm{CO}_{2}$ adsorbed. At a flow time of 5 minutes, $5.5 \mathrm{mmol}$ of $\mathrm{CO}_{2}$ was adsorbed per gram of adsorbent, and the values were increased to 12.5 and 13.5 mmol for flow times of 10 and 15 minutes, respectively. In addition, the $\mathrm{CO}_{2}$ adsorption capacity of Ni-phen/MC is higher than that of the $\mathrm{MC}$ adsorbent, which is only $1.1 \mathrm{mmol}$ of $\mathrm{CO}_{2}$ at a flow time of 10 minutes (11 times higher). These results suggest that the presence of $\mathrm{Ni}$ phen complex plays an important role in improving the adsorption capacity of mesoporous carbon. This can occur since the $\mathrm{Ni}$ species in the complex could bind to $\mathrm{CO}_{2}$ molecule through several binding methods as shown in Figure 7. The results also show that the $\mathrm{CO}_{2}$ adsorption capacity of $\mathrm{Ni}$-phen/MC is higher than that of other mesoporous carbon-based materials such as amine-modified MC [20,22],

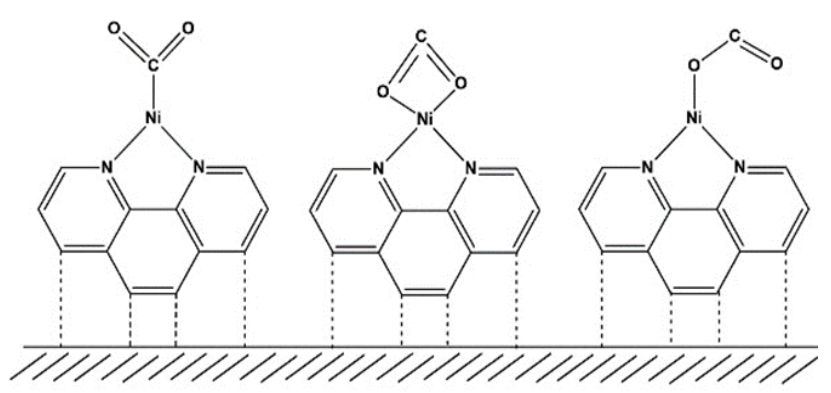

Figure 7. Proposed $\mathrm{Ni}-\mathrm{CO}_{2}$ interactions on $\mathrm{Ni}$ phen/MC.

Table 2. Surface properties of MC and Ni-phen/MC.

\begin{tabular}{lcccccccc}
\hline Sample & $\begin{array}{c}S_{\mathrm{BET}^{\mathrm{a}}} \\
\left(\mathrm{m}^{2} / \mathrm{g}\right)\end{array}$ & $\begin{array}{c}S_{\mathrm{ext}^{\mathrm{b}}} \\
\left(\mathrm{m}^{2} / \mathrm{g}\right)\end{array}$ & $\begin{array}{c}S_{\mathrm{mic}^{\mathrm{b}}} \\
\left(\mathrm{m}^{2} / \mathrm{g}\right)\end{array}$ & $\begin{array}{c}V_{\mathrm{tot}^{\mathrm{c}}} \\
(\mathrm{cc} / \mathrm{g})\end{array}$ & $\begin{array}{c}V_{\text {meso }^{\mathrm{d}}} \\
(\mathrm{cc} / \mathrm{g})\end{array}$ & $\begin{array}{c}V_{\text {mic }^{\mathrm{c}}} \\
(\mathrm{cc} / \mathrm{g})\end{array}$ & $\begin{array}{c}\text { Pore radius } \\
(\mathrm{nm})\end{array}$ & $\begin{array}{c}\text { Pore diameter } \\
(\mathrm{nm})\end{array}$ \\
\hline $\mathrm{MC}$ & 364.873 & 274.6786 & 90.194 & 0.615 & 0.5664 & 0.045 & 3.3587 & 6.7174 \\
Ni-phen/MC & 165.59 & 156.2344 & 9.3556 & 2.1869 & 2.1838 & 9.3556 & 2.54 & 5.08 \\
\hline
\end{tabular}

acalculated by BET method; bdetermined by t-plot; ccalculated by BJH desorption method; dcalculated by $\mathrm{V}_{\text {total }}-\mathrm{V}_{\text {micro }}$

Table 3. Comparison of $\mathrm{CO}_{2}$ adsorption capacities of some mesoporous carbon-based materials.

\begin{tabular}{lcc}
\hline Material & $\mathrm{CO}_{2}$ adsorption capacity $(\mathrm{mmol} / \mathrm{g})$ & Ref \\
\hline TETA-modified MC & 10.9 & {$[20]$} \\
N-doped MC & 5.7 & {$[21]$} \\
NiNPs on N-doped MC & 5.5 & {$[21]$} \\
MDEA-modified MC & 2.6 & {$[22]$} \\
PANI/MC & 5.6 & {$[23]$} \\
Ni(phen)-modified MC & 13.5 & This work \\
\hline
\end{tabular}


NiNPs-doped MC [21], and PANI/MC nanocomposite [23] (see Table 3 for details). This indicates the superiority of Ni-phen complex in binding to $\mathrm{CO}_{2}$ compared to only amine functional group or nickel metal alone on MC.

\subsection{Carboxylation Reaction of Phenylacetylene} with $\mathrm{CO}_{2}$

Based on previous studies [6,7] it is known that the homogeneous nickel-catalyzed carbox-
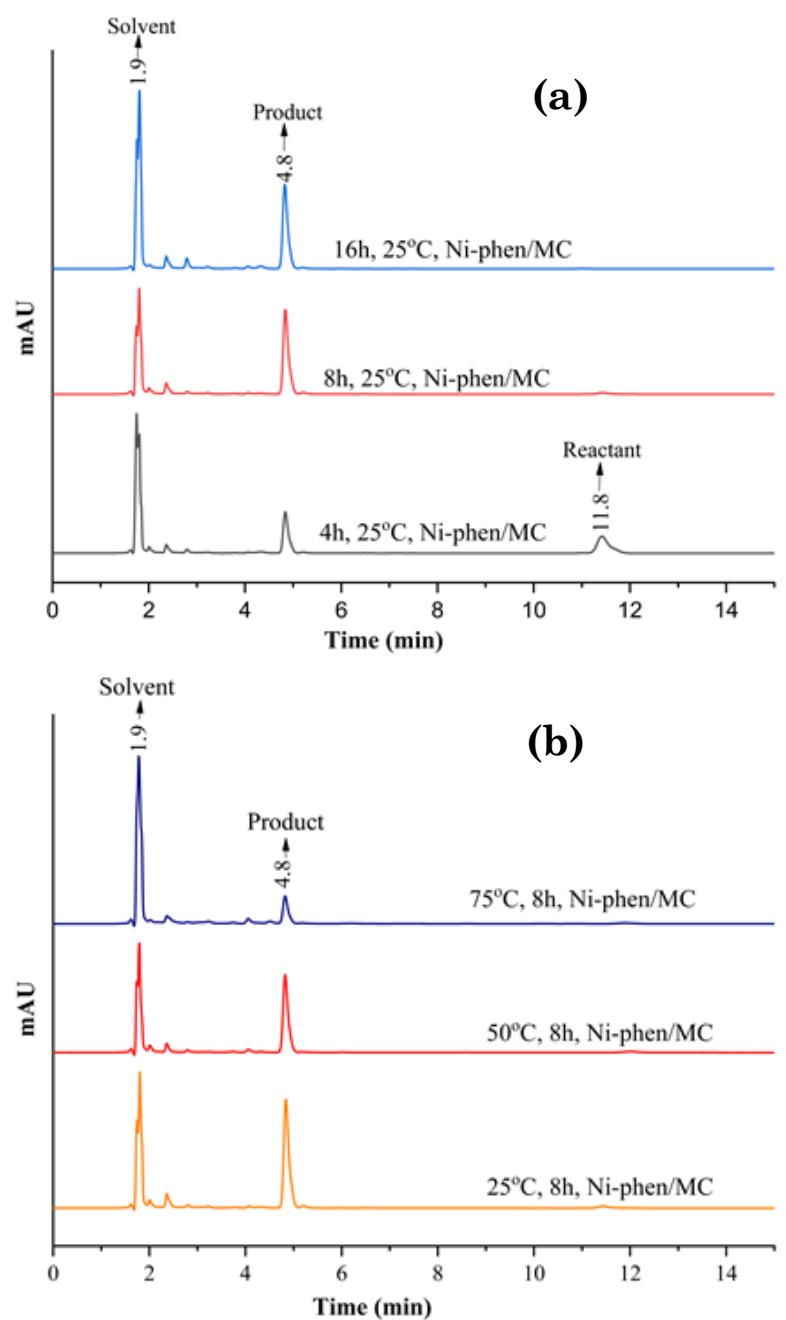

ylation of an alkyne could give two type of products, single- and double-carboxylation product. In the case of phenylacetylene as a substrate, the product could be cinnamic acid or 2-phenylmaleic acid, as shown in Scheme 1. Therefore, we investigate the reaction mixture by using the two product standards to determine the product of our Ni-phen/MC-catalysed carboxylation reaction. HPLC analysis of the standard shows that cinnamic acid appears at retention time of $6.1 \mathrm{~min}, 2$-phenylmaleic acid at around $4.8 \mathrm{~min}$, whereas phenylacetylene reactant at around 11.7 minutes. Thus, according to HPLC chromatogram of various reaction mixture in Figure 8, the Ni-phen/MC catalysed carboxylation of phenylacetylene gave 2phenylmaleic acid as the product. This means that the reaction proceeded via a double carboxylation as reported by Fujihara [6].

Various reaction conditions such as reaction time and reaction temperature were examined to investigate their effect to the formation of product. The results are shown in Table 4 and Figure 8. Conducting the reaction at longer reaction time, clearly improve the amount of the product. However, we observed there is no sig-

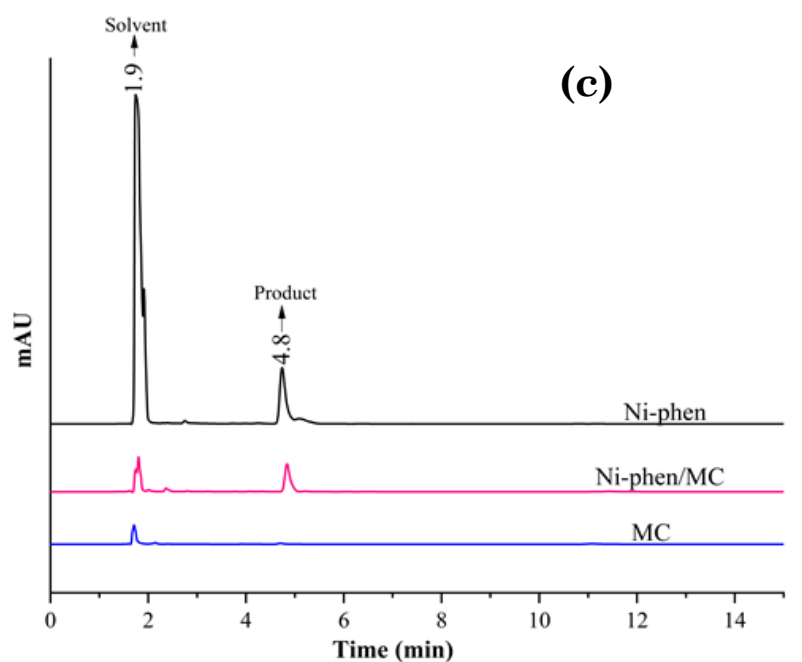

Figure 8. HPLC chromatogram of reaction mixture of phenylacetylene carboxylation under various conditions: (a) variation of time, (b) variation of temperature, and (c) variation of catalyst type.

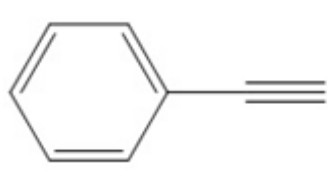

Phenylacetylene

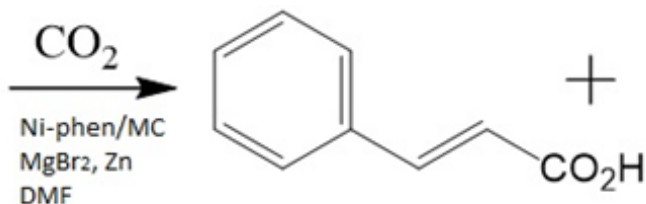

Cinnamic acid

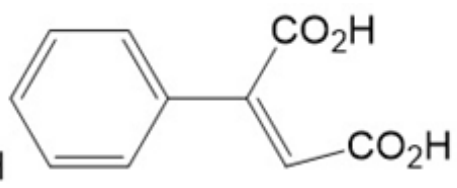

2-Phenylmaleic acid

Scheme 1. Carboxylation of phenylacetylene catalysed by Ni-phen/MC in the presence of $\mathrm{MgBr}_{2}$ as an additive, $\mathrm{Zn}$ powder as a reducing agent in $\mathrm{DMF}$ solvent under an atmospheric $\mathrm{CO}_{2}$ pressure. 
nificant difference for conducting the reaction for 8 and $16 \mathrm{~h}$ indicating that all reactants have been completely consumed after $8 \mathrm{~h}$ (Figure 8(a)). In contrast, temperature has the opposite effect to the reaction time, where an increase in temperature causes a decrease in the product formed. It can be understood that at higher temperatures, the solubility of $\mathrm{CO}_{2}$ in the reaction medium (DMF) decreases, resulting in less products formed for the same reaction time (Figure 8(b)). We also compare the catalytic activity of Ni-phen/MC catalyst to the homogeneous Ni-phen catalyst and to $\mathrm{MC}$ alone as comparison. As the result, the heterogeneous Ni-phen/MC catalysts gave a product nearly half the amount of that formed from a homogeneous Ni-phen catalyst. This shows that the heterogeneous catalysts provide good prospects for further development in the future. The lower activity of the heterogeneous catalysts is understandable considering that the active site of the catalyst is less exposed than that in the homogeneous catalysts, in which the Ni-phen complex as an active species is free to move in the solvent medium and can interact with reactants on various sides. Meanwhile, when the reaction was carried out using $\mathrm{MC}$ in place of Ni-phen/MC, almost no product was formed. This result indicates that nickel is indeed the active species in the carboxylation reaction of phenylacetylene with $\mathrm{CO}_{2}$. Although $\mathrm{MC}$ has a surface area twice as large as Ni-phen/MC, the absence of an active catalyst causes the carboxylation reaction with $\mathrm{CO}_{2}$ to not proceed.

\section{Conclusion}

The heterogenization of nickelphenanthroline complex was successfully conducted by immobilization on mesoporous carbon as a solid support as indicated by several characterization such as FTIR and SEM-EDX. The presence of the nickel complex on mesoporous carbon reduces the pore diameter and surface area of the support. However, the adsorption activity towards $\mathrm{CO}_{2}$ increases due to the interaction between $\mathrm{CO}_{2}$ with nickelphenanthroline complex. Furthermore, the Niphen/MC catalyst show good performance in catalyzing the carboxylation reaction of phenylacetylene under an atmospheric $\mathrm{CO}_{2}$ pressure.

\section{Acknowledgments}

This work was funded by Kemenristek / BRIN No NKB-2812/UN2.RST/ HKP.05.00/2020.

\section{References}

[1] Juliá-Hernández, F., Gaydou, M., Serrano, E., Gemmeren, M. van, Martin, R. (2016). Niand Fe-catalyzed Carboxylation of Unsaturated Hydrocarbons with $\mathrm{CO}_{2}$. Topics in Current Chemistry, 374(45), 1-39, doi: 10.1007/s41061-016-0045-z.

[2] Liu, Q., Wu, L., Jackstell, R., Beller, M. (2015). Using carbon doxide as a building block in organic synthesis. Nature Communications, 6, 5933, doi: 10.1038/ncomms6933.

[3] Song, Q.-W., Zhou, Z.-H., He, L.-N. (2017). Efficient, selective and sustainable catalysis of carbon dioxide. Green Chemistry, 19(16), 3707-3728, doi: 10.1039/c7gc00199a.

Table 4. HPLC chromatogram area of main product (retention time of $4.8 \mathrm{~min}$ ).

\begin{tabular}{|c|c|c|}
\hline \multicolumn{2}{|c|}{ Reaction conditions } & \multirow{2}{*}{$\frac{\text { Area }(\mathrm{mAU})}{17.9242}$} \\
\hline \multirow{3}{*}{ Variation of time $(\mathrm{h})^{\mathrm{a}}$} & 4 & \\
\hline & 8 & 36.9333 \\
\hline & 16 & 36.1110 \\
\hline \multirow{3}{*}{$\begin{array}{l}\text { Variation of temperature } \\
\qquad\left({ }^{\circ} \mathrm{C}\right)^{\mathrm{b}}\end{array}$} & 25 & 36.9392 \\
\hline & 50 & 26.0194 \\
\hline & 75 & 9.5203 \\
\hline \multirow{3}{*}{ Variation of catalyst type ${ }^{c}$} & Ni-phen & 86.4172 \\
\hline & Ni-phen/MC & 36.9041 \\
\hline & $\mathrm{MC}$ & 1.7796 \\
\hline
\end{tabular}

areactions were conducted at $25^{\circ} \mathrm{C}$ using $\mathrm{Ni}$-phen/MC as a catalyst; breactions were conducted for $8 \mathrm{~h}$ using Ni-phen/MC as a catalyst; 'reactions were conducted at $25^{\circ} \mathrm{C}$ for $8 \mathrm{~h}$. 
[4] Leung, C.-F., Ho, P.-Y. (2019). Molecular catalysis for utilizing $\mathrm{CO}_{2}$ in fuel electrogeneration and in chemical feedstock. Catalysts, 9(9), 760, doi: 10.3390/catal9090760.

[5] Fujihara, T., Nogi, K., Xu, T., Terao, J., Tsuji, Y. (2012). Nickel-Catalyzed Carboxylation of Aryl and Vinyl Chlorides Employing Carbon Dioxide. Journal of the American Chemical Society, 134(22), 9106-9109, doi: 10.1021/ja303514b.

[6] Fujihara, T., Horimoto, Y., Mizoe, T., Sayyed, F. B., Tani, Y., Terao, J., Sakaki, S., Tsuji, Y. (2014). Nickel-Catalyzed Double Carboxylation of Alkynes Employing Carbon Dioxide. Organic Letters, 16(18), 4960-4963, doi: 10.1021/ol502538r.

[7] Doi, R., Abdullah, I., Taniguchi, T., Saito, N., Sato, Y. (2017). Nickel-catalyzed hydrocarboxylation of ynamides with $\mathrm{CO}_{2}$ and $\mathrm{H}_{2} \mathrm{O}$ : Observation of unexpected regioselectivity. Chemical Communications, 53(55), 77207723, doi: 10.1039/C7CC03127K.

[8] Doi, R., Okano, T., Abdullah, I., Sato, Y. (2019). Nickel-catalyzed b-carboxylation of ynamides with carbon dioxide. Synlett, 30(9), 1048-1052, doi: 10.1055/s-0037-1611529

[9] Górka, J., Zawislak, A., Choma, J., Jaroniec, M. (2008). KOH activation of mesoporous carbons obtained by soft-templating. Carbon, 46, 1159-1174, doi: 10.1016/j.carbon.2008.03.024.

[10] Yuan, D., Yuan, X., Zou, W., Zeng, F., Huang, X., Zhou, S. (2012). Synthesis of graphitic mesoporous carbon from sucrose as a catalyst support for ethanol electro-oxidation. Journal of Materials Chemistry, 22, 17820-17826, doi: 10.1039/C2JM33658H.

[11] Nanaji, K., Jyothirmayi, A., Varadaraju, U., Rao, T.N., Anandan, S. (2017). Facile synthesis of mesoporous carbon from furfuryl alcohol-butanol system by EISA process for supercapacitors with enhanced rate capability. Journal of Alloys and Compounds, 723(5), 488-497, doi: 10.1016/j.jallcom.2017.06.231.

[12] Liu, L., Wang, F.-Y., Shao, G.-S., Ma, T.-Y., Yuan, Z.-Y. (2010). Synthesis of ultra-large mesoporous carbons from triblock copolymers and phloroglucinol/formaldehyde polymer. Carbon, 48(9), 2660-2664, doi: 10.1016/j.carbon.2010.03.035.

[13] Ignat, M., Sacarescu, L., Cool, P., Harabagiu, V. (2015). Glycerol-derived Mesoporous Carbon: $\mathrm{N}_{2}$-sorption and SAXS Data Evaluation. Materials Today: Proceedings, 2(6), 38363845, doi: 10.1016/j.matpr.2015.08.012.

[14] Ulfa, M., Trisunaryanti, W., Falah, I.I., Kartini, I. (2016). Wormhole-Like Mesoporous Carbons from Gelatine as Multistep Infiltration Effect. Indonesian Journal of Chemistry, 16(3), 239 - 242, doi: 10.22146/ijc.21137.
[15] Hadi, A., Abdullah, I., Krisnandi, Y.K. (2020). Preliminary study on carboxylation reaction of phenylacetylene with $\mathrm{CO}_{2}$ using nickel catalyst impregnated on mesoporous carbon. IOP Conference Series: Materials Science and Engineering, 763, 012008, doi: 10.1088/1757899X/763/1/012008.

[16] Lestari, W.W., Wibowo, A.H., Astuti, S., Irwinsyah, I., Pamungkas, A.Z., Krisnandi, Y.K. (2018). Fabrication of hybrid coating material of polypropylene itaconate containing MOF-5 for $\mathrm{CO}_{2}$ capture. Progress in Organic Coatings, $115, \quad 49-55, \quad \mathrm{doi}$ : 10.1016/j.porgcoat.2017.11.006.

[17] Amalia, P.N., Abdullah, I., Rahayu, D.U.C., Krisnandi, Y.K. (2021). Synthesis and Characterization of Copper Impregnated Mesoporous Carbon as Heterogeneous Catalyst for Phenylacetylene Carboxylation with Carbon Dioxide. Indonesian Journal of Chemistry, 21(1), 77-87, doi: 10.22146/ijc.52778.

[18] Liang, C., Dai, S. (2006). Synthesis of Mesoporous Carbon Materials via Enhanced Hydrogen-Bonding Interaction. Journal of the American Chemical Society, 128(16), 53165317, doi: 10.1021/ja060242k.

[19] Tabatabaee, M., Zaji, N., Parvez, M. (2011). Tris(1,10-phenanthroline- $\left.k^{2} \mathrm{~N}, \mathrm{~N}^{\prime}\right)$-nickel(II) dinitrate tetrahydrate. Acta Crystallographic a , 67, $1794-1795, \quad \mathrm{~d}$ o i : 10.1107/S160053681104880X.

[20] Sulistianti, I., Krisnandi, Y.K., Moenandar, I. (2017). Study of $\mathrm{CO}_{2}$ adsorption capacity of mesoporous carbon and activated carbon modified by triethylenetetramine (TETA). IOP Conference Series: Materials Science and Engineering, 188, 012041, doi: 10.1088/17426596/755/1/011001.

[21] Pamungkas, A.Z., Abdullah, I., Krisnandi, Y.K. (2019). Synthesis and characterization of $\mathrm{Ni}$ nanoparticles supported on nitrogen-doped mesoporous carbon. IOP Conference Series: Materials Science and Engineering, 496, 012003 , doi: $10.1088 / 1757$. 899X/496/1/012003.

[22] Ardhyarini, N., Krisnandi, Y.K. (2017). Carbon dioxide capture by activated methyl diethanol amine impregnated mesoporous carbon. AIP Conference Proceedings, 1862, 030090, doi: 10.1063/1.4991194.

[23] Anbia, M., Salehi, S. (2016). Synthesis of polyaniline/mesoporous carbon nanocomposites and their application for $\mathrm{CO}_{2}$ sorption. Journal of Polymer Research, 23(7), 124. doi: 10.1007/s10965-016-1014-5. 